\title{
DFT Study of the Asymmetric Nitroaldol (Henry) Reaction Catalyzed by a Dinuclear Zn Complex
}

\author{
NA QI, RONG-ZHEN LIAO, JIAN-GUO YU, RUO-ZHUANG LIU \\ College of Chemistry, Beijing Normal University, Beijing 100875, China \\ Received 19 March 2009; Revised 22 July 2009; Accepted 20 August 2009 \\ DOI 10.1002/jcc.21422 \\ Published online 17 December 2009 in Wiley InterScience (www.interscience.wiley.com).
}

\begin{abstract}
We report the mechanism of asymmetric nitroaldol (Henry) reaction catalyzed by a dinuclear $\mathrm{Zn}$ complex using density functional theory. The experimentally proposed catalytic cycle is validated, in which the first step is the deprotonation of nitromethane by the ethyl anion of the catalyst, subsequently a $\mathrm{C}-\mathrm{C}$ bond formation step, and then the protonation of the resulting alkoxide. Three mechanistic scenarios (differing in binding modes) have been considered for the $\mathrm{C}-\mathrm{C}$ bond formation step. The origin of the enantioselectivity is discussed. Our calculations supported that the S configurations are the major products, which is in agreement with the experimental observations.
\end{abstract}

(C) 2009 Wiley Periodicals, Inc. J Comput Chem 31: 1376-1384, 2010

Key words: nitroaldol (Henry) reaction; density functional theory; enantioselectivity; dinuclear $\mathrm{Zn}$ catalyst

\section{Introduction}

The Henry or nitroaldol reaction, between carbonyl compounds and nitroalkanes, constitutes a very important synthetic method for the construction of carbon-carbon bonds in organic chemistry. ${ }^{1}$ The resulting $\beta$-nitroaldols, especially in an optically active form, are useful precursors to a variety of valuable functionalized structural motifs, such as $\beta$-amino alcohols, $\alpha$-hydroxy carboxylic acids, etc. These derivatives are common building blocks presented in biologically active nature products and pharmaceuticals. $^{2}$ Consequently, considerable efforts have been made toward the development of efficient asymmetric catalysts for this kind of reactions with impressive breakthrough achieved over the last two decades. ${ }^{3,4}$

With the presence of a number of environmentally friendly organocatalysts for the nitroaldol reaction, many bifunctional metal/chiral ligand complexes have also been described with high efficiency, including lanthanoid, ${ }^{5-7} \mathrm{Zn},{ }^{8-11} \mathrm{Cu},{ }^{12-15}$ and $\mathrm{Co}^{16,17}$ complexes. Apparently, zinc-based catalysts are especially interesting because they parallel class II aldolase enzymes in the light of relying on zinc. ${ }^{18}$ Several efficient mononuclear zinc catalysts with different chiral ligands have been developed for this reaction, such as chiral amino alcohol, ${ }^{9}$ bisoxazolidine, ${ }^{10}$ and ferrocenyl-substituted aziridinylmethanol. ${ }^{11}$ In addition, some other mononuclear Zn-based catalysts have also been reported, however, with lower enantiomeric excesses. ${ }^{19}$ Beside these mononuclear zinc catalysts, Trost and $\mathrm{Yeh}^{8}$ reported the first asymmetric dinuclear zinc complexes 1 with a chiral semiazacrown ligands (see Scheme 1), which were found to be efficient catalysts for inducing unparalleled enantioselectivity.
The dinuclear zinc catalyst designed by Trost also led to a number of other efficient, catalytic, enantioselective transformations, including aldol reactions, ${ }^{20-24}$ Mannich reactions, ${ }^{25,26}$ Michael addition, ${ }^{27}$ alkynylations of aldehydes, ${ }^{28}$ desymmetrizations of meso 1,3-diols, ${ }^{29}$ and Friedel-Crafts alkylations. ${ }^{30}$ The catalyst has also been successfully applied in natural product synthesis and other important chemical reactions. ${ }^{31-34}$ For nitroaldol reactions, Trost proposed a possible catalytic cycle, as depicted in Scheme 2. The initial step of the reaction is deprotonation of nitromethane by the ethyl anion attached to one of the zinc ions in the catalyst, resulting in the formation of a zinc nitronate intermediate and 1 equiv of ethane. Coordinations of the aldehyde to the other zinc ion undergo the $\mathrm{C}-\mathrm{C}$ bond formation between the nitronate carbon and the aldehyde carbon. Finally, the association of nitromethane followed by a proton transfer to the oxygen anion produced in the previous step gives the product and restart the catalytic cycle. ${ }^{8}$

A number of zinc-catalyzed reactions have been investigated by means of quantum chemical methods. ${ }^{35-39}$ However, accord-

\footnotetext{
Additional Supporting Information may be found in the online version of this article.

The first two authors contributed equally to this paper.

Correspondence to: J-G. Yu; e-mail: jianguo_yu@bnu.edu.cn

Contract/grant sponsor: National Natural Science Foundation of China; contract/grant numbers: 20733002, 20873008

Contract/grant sponsor: Major State Basic Research Development Programs; contract/grant number: 2004CB719903
} 


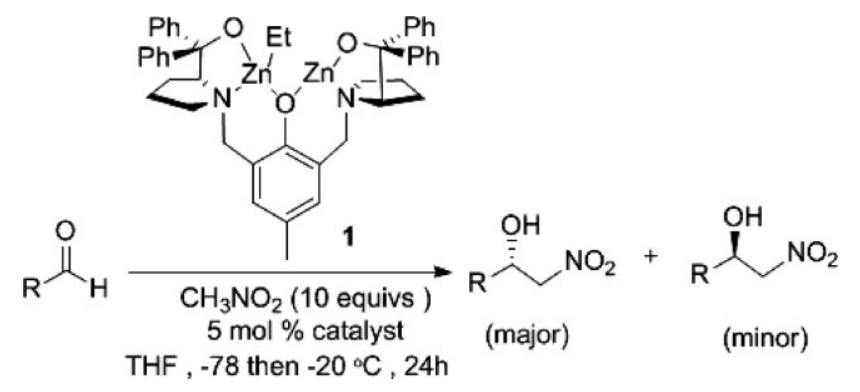

Scheme 1. Catalyzed asymmetric Henry reaction.

ing to our knowledge, little theoretical attention has been paid for this dinuclear zinc catalyst. Despite the great achievements in the experimental area on the study of the reaction, insight into the energetic, the detailed mechanism and the origin of the enantioselectivity of this catalytic reaction are still lacking. These have prompted our theoretical investigation for the mechanism of the reaction catalyzed by this binuclear $\mathrm{Zn}$ catalyst. In our present study, we performed the density functional calculations with the well-established B3LYP functional, ${ }^{40,41}$ and chose the benzaldehyde and nitromethane as substrates, yielding 2-nitro-1-phenylethanol (see Scheme 3). Our calculations are relevant to further understanding of many other reactions catalyzed by this dinuclear $\mathrm{Zn}$ catalyst.

\section{Computational Details}

All calculations were performed at the density functional theory (DFT) level with the B3LYP functional as implemented in the Gaussian 03 package. ${ }^{42}$ For the geometry optimizations, the 6$31 \mathrm{G}(d, p)$ basis sets were used for the $\mathrm{C}, \mathrm{N}, \mathrm{O}$, and $\mathrm{H}$ elements and the SDD pseudopotential ${ }^{43}$ for $\mathrm{Zn}$. Based on the optimized geometries, more accurate energies were obtained by performing singlepoint calculations with the $6-311++\mathrm{G}(2 d, 2 p)$ basis sets for all elements. All geometries were optimized in vacuo. To estimate the energetic effects of the THF $(\varepsilon=7.58)$ environment, solvation effects were calculated at the same theory level as the optimizations by performing single-point calculations on the optimized structures using the conductor-like polarizable continuum model (CPCM) method. ${ }^{44-47}$ Frequency calculations were performed at the same theory level as the optimizations to obtain zero-point energies (ZPE) and to confirm the nature of all stationary points. The latter implied no negative eigenvalues for minima and only one negative eigenvalue for transition states. The energies reported herein were corrected for both solvation and zero-point vibrational effects.

To compare the results obtained with the B3LYP method, we also used a new hybrid density functional BB1K that has recently been shown to produce results for accurate potential energy surface (PES) calculation of reactions. ${ }^{48}$ Based on the optimized geometries with B3LYP for some important configurations, we carried out single-point calculations by $\mathrm{BB} 1 \mathrm{~K}$, and the 6-31G $(d, p)$ basis sets were used for the $\mathrm{C}, \mathrm{N}, \mathrm{O}$, and $\mathrm{H}$ elements and the SDD pseudopotential for $\mathrm{Zn}$. Additionally, singlepoint calculations with the $6-311++\mathrm{G}(2 d, 2 p)$ basis sets for all elements were also carried out to get more accurate energies. All results have been corrected for both solvation in THF and zero-point vibrational effects.

\section{Results and Discussion}

Based on our calculations, it was found that the catalytic reaction involves three chemical steps: (1) deprotonation of nitrome-

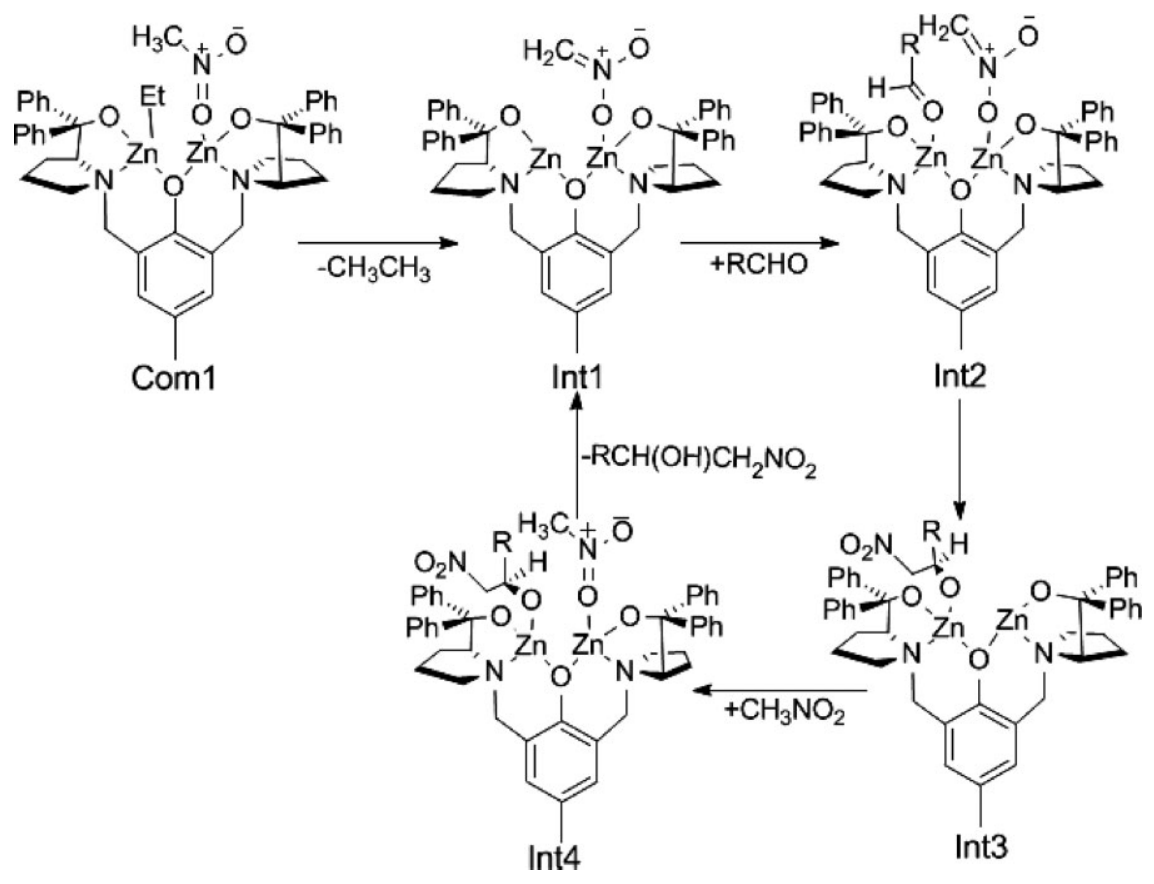

Scheme 2. Proposed catalytic cycle for the Henry reaction. ${ }^{8}$ 


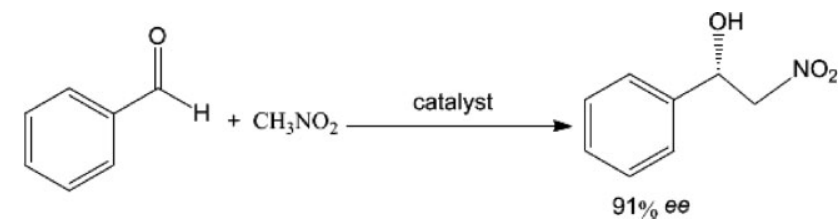

Scheme 3. The Henry reaction between benzaldehyde and nitromethane discussed in this paper.

thane, (2) $\mathrm{C}-\mathrm{C}$ bond formation, and (3) proton transfer and regeneration of the reactive species.

\section{Step 1: Deprotonation}

The first step is the deprotonation of nitromethane by the ethyl anion coordinated to $\mathrm{Zn} 1$ in $\mathrm{Com} 1\left(\mathrm{Com} 1_{\mathrm{A}}\right.$ and $\mathrm{Com} 1_{\mathrm{B}}$, see Supporting Information) with the formation of Int 1 and ethane. Because of the coordination of nitromethane to $\mathrm{Zn} 2$, the energy of $\mathrm{Com}_{\mathrm{A}}$ is $9.7 \mathrm{kcal} / \mathrm{mol}$ lower than that of isolated reactants in the gas phase and $5.7 \mathrm{kcal} / \mathrm{mol}$ in the THF. Two plausible mechanistic pathways have been considered, one is with the retention of the carbon configuration, marked as $\mathrm{I}_{\mathrm{A}}$, whereas the second is with the inversion of the carbon configuration, marked as $I_{B}$. The corresponding transition states are labeled as $\mathrm{TS}_{\mathrm{A}}$ and $\mathrm{TS}_{\mathrm{B}}$ (Fig. 1) with the barriers to be 20.6 (22.6) $\mathrm{kcal} / \mathrm{mol}$ (energies in parenthesis correspond to calculations in gas phase) relative to $\mathrm{Com}_{\mathrm{A}}$ and 20.4 (22.3) $\mathrm{kcal} / \mathrm{mol}$ relative to $\mathrm{Com} 1_{\mathrm{B}}$ including THF solvation effect (Fig. 2), respectively. However, $\mathrm{TS} 1_{\mathrm{A}}$ is $1.8 \mathrm{kcal} / \mathrm{mol}$ ( $4.4 \mathrm{kcal} / \mathrm{mol}$ by the $\mathrm{BB} 1 \mathrm{~K}$ method) lower than $\mathrm{TS}_{\mathrm{B}}$. These results indicate that the retention pathway is more favorable. At $\mathrm{TS} 1_{\mathrm{A}}$, the two $\mathrm{C}-\mathrm{H}$ distances are 1.349 and $1.484 \AA$, respectively, and the angle between $\mathrm{C}-\mathrm{H}-\mathrm{C}$ is $164.2^{\circ}$; whereas at $\mathrm{TS} 1_{\mathrm{B}}$, the two $\mathrm{C}-\mathrm{H}$ distances are $1.395 \AA$ and $1.487 \AA$, and the angle is $154.9^{\circ}$; (Fig. 1).

This step is exothermic by over $30 \mathrm{kcal} / \mathrm{mol}$ from our calculations (Fig. 2), indicating that the proton transfer is energetically quite feasible. The reason may be the large difference of the relative $\mathrm{pKa}$ between nitromethane and ethane.

\section{Step 2: Carbon-Carbon Bond Formation}

With the formation of a reactive nitronate species in Int1, the benzaldehyde can easily undergo a nucleophilic attack with the formation of $\mathrm{C}-\mathrm{C}$ bond. Three plausible binding modes of the nucleophile to $\mathrm{Zn} 2$ have been considered, which are marked as pathways A, B, C. The fragment structures of the reactants (Int2) leading to S-products and R-products are shown in Figure 3.

In pathway $\mathrm{A}$, the nitronate is coordinated to the dinuclear zinc center in a bidentate fashion (Fig. 3), with the Zn1-O and $\mathrm{Zn} 2-\mathrm{O}$ distances of 2.131 and $1.975 \AA$ in Int $2_{\mathrm{SA}}, 2.117$ and $1.967 \AA$ in Int $2_{\mathrm{RA}}$, respectively. The structures of the transition states (TS2 $2_{\mathrm{SA}}$ and $\mathrm{TS} 2_{\mathrm{RA}}$ in Fig. 4) that lead to both $\mathrm{S}$ and $\mathrm{R}$ products have been located. $\mathrm{TS}_{\mathrm{SA}}$ is $9.1(9.8) \mathrm{kcal} / \mathrm{mol}$ higher in energy than Int $2_{\mathrm{SA}}$, whereas $\mathrm{TS} 2_{\mathrm{RA}}$ is $13.3(12.2) \mathrm{kcal} / \mathrm{mol}$ higher than Int $2_{\mathrm{RA}}$. The $\mathrm{C}-\mathrm{C}$ distances in $\mathrm{TS} 2_{\mathrm{SA}}$ and $\mathrm{TS} 2_{\mathrm{RA}}$ are 2.143 and $2.011 \AA$, respectively. In addition, the corresponding dihedral angles of O31-C30-C29-N27 in both transition states (Fig. 4) are $27.2^{\circ}$ and $-9.3^{\circ}$, respectively. Downhill from the transition states, the nitroalkoxide catalyst complex (Int3, see SI) is formed, and the energies of Int $3_{\mathrm{SA}}$ and $\operatorname{Int} 3_{\mathrm{RA}}$ are 5.4 and 4.3 $\mathrm{kcal} / \mathrm{mol}$ relative to Int $2_{\mathrm{SA}}$ and Int $2_{\mathrm{RA}}$, respectively. During the step of $\mathrm{C}-\mathrm{C}$ bond formation, the negative charge is transferred from the nitronate oxygen to benzaldehyde oxygen. In Int $3_{\mathrm{SA}}$, the newly formed oxyanion is stabilized by $\mathrm{Zn} 1$ with the corresponding distance of $1.910 \AA$. But the oxyanion is coordinated to both $\mathrm{Zn}$ ions in Int $3_{\mathrm{RA}}$, with the $\mathrm{Zn1-O31}$ and $\mathrm{Zn2-O} 31$ distances of 1.968 and $2.052 \AA$, respectively. Both $\mathrm{Zn}$ ions provide electrostatic stabilization on both the transition states and intermediates, thereby lowering the barrier for the $\mathrm{C}-\mathrm{C}$ bond formation.

In pathway $\mathrm{B}$, the nitronate is coordinated to $\mathrm{Zn} 2$ with both oxygen atoms (Fig. 3). The calculated $\mathrm{Zn}-\mathrm{O}$ distances are 2.194 and $2.098 \AA$ in Int $2_{\mathrm{SB}}$, and 2.195 and $2.094 \AA$ in Int $2_{\mathrm{RB}}$, respectively. The barriers for the $\mathrm{C}-\mathrm{C}$ bond formation starting from these structures are $6.3(5.1) \mathrm{kcal} / \mathrm{mol}$ for the $\mathrm{S}$-product $\left(\mathrm{Int} 3_{\mathrm{SB}}\right)$ and $9.0(6.6) \mathrm{kcal} / \mathrm{mol}$ for the R-product (Int $3_{\mathrm{RB}}$ ). The key $\mathrm{C}-\mathrm{C}$ distances are $2.132 \AA$ and $2.053 \AA$ in $\mathrm{TS} 2_{\mathrm{SB}}$ and $\mathrm{TS} 2_{\mathrm{RB}}$ (Fig. 4), respectively. Additionally, the dihedral angles of O31-C30-C29-N27 in $\mathrm{TS} 2_{\mathrm{SB}}$ and $\mathrm{TS} 2_{\mathrm{RB}}$ are $40.5^{\circ}$ and $34.7^{\circ}$, respectively. The energy of the Int $3_{\mathrm{SB}}$ lies at $-4.2 \mathrm{kcal} / \mathrm{mol} \mathrm{rel}-$ ative to Int $2_{\mathrm{SB}}$, whereas that of $\operatorname{Int} 3_{\mathrm{RB}}$ is $8.6 \mathrm{kcal} / \mathrm{mol}$ higher than Int $2_{\mathrm{RB}}$. It can be seen from Figure 5 that the formation of $\mathrm{R}$-product through pathway $\mathrm{B}$ is not favorable since the barrier for the reverse step is just $0.4 \mathrm{kcal} / \mathrm{mol}$. The transfer of Int $3_{\mathrm{RB}}$ to Int $3_{\mathrm{RC}}$ or Int $3_{\mathrm{RA}}$ should require at least several $\mathrm{kcal} / \mathrm{mol}$, indicating that the formation of R-product through pathway $\mathrm{B}$ is not competitive with pathway $\mathrm{A}$, although $\mathrm{TS} 2_{\mathrm{RB}}$ is only $0.2 \mathrm{kcal} /$ mol lower than TS2 $2_{\mathrm{RA}}$.

Based on our calculations, in pathway $\mathrm{C}$, an oxygen atom of the nitronate is coordinated to both $\mathrm{Zn}$ ions (Fig. 3), with the $\mathrm{Zn} 1-\mathrm{O}$ and $\mathrm{Zn2-O}$ distances of 2.163 and $1.990 \AA$ in Int2 ${ }_{\mathrm{SC}}$, 2.132 and $1.987 \AA$ in Int $2_{\mathrm{RC}}$. The transition states of $\mathrm{C}-\mathrm{C}$ bond formation from Int $2_{\mathrm{SC}}$ and $\mathrm{Int} 2_{\mathrm{RC}}\left(\mathrm{TS} 2_{\mathrm{SC}}\right.$ and $\mathrm{TS} 2_{\mathrm{RC}}$, see Fig. 4) are located with the $\mathrm{C}-\mathrm{C}$ bond distance of 2.255 and 2.258 $\AA$, with the energetic barriers of 7.3 (7.2) and 4.5 (5.2) kcal/mol, respectively. Furthermore, the dihedral angle of O31-C30-C29$\mathrm{N} 27$ in the TS structures was calculated as $69.1^{\circ}$ and $63.3^{\circ}$. The reaction of this pathway for the formation of $\mathrm{S}$ and $\mathrm{R}$ products (Int $3_{\mathrm{SC}}$ and $\mathrm{Int} 3_{\mathrm{RC}}$ ) is exothermic by 7.2 and $7.7 \mathrm{kcal} / \mathrm{mol}$, respectively. In both $\mathrm{Int} 3_{\mathrm{SC}}$ and $\mathrm{Int} 3_{\mathrm{RC}}$, the nitroalkoxide oxygen anion is bridging the two $\mathrm{Zn}$ ions (see $\mathbf{S I}$ ).

In the three pathways discussed above, according to their relative reaction barriers, the pathway $\mathrm{A}$ is energetically the most favorable (see Fig. 5), whereas the pathway B is next. There could be a couple of reasons. One reason for the order could be that the Int $2_{\mathrm{SA}}$ and Int $2_{\mathrm{RA}}$ adopt an energetically more feasible conformation, evidenced by the relative energies of six reactants in this step (see Fig. 5). Another reason might be the stronger interactions between $\mathrm{Zn} 1$ and $\mathrm{n}$ electrons of O31. At TS2, O31 changes from $s p 2$ hybridization in Int2 to partially $s p 3$ hybridization. The angle of $\mathrm{C} 30-\mathrm{O} 31-\mathrm{Zn} 1$ (labeled as $\alpha$ in Fig. 4) is $123.0^{\circ}$ in $\mathrm{TS} 2_{\mathrm{SA}}$. However, the angles are $129.4^{\circ}$ in $\mathrm{TS} 2_{\mathrm{SB}}$ and $135.7^{\circ}$ in $\mathrm{TS} 2_{\mathrm{SC}}$.

The overall reaction between nitromethide and benzaldehyde yielding nitroalkoxide (Re, TS, and $\operatorname{Pr}$ in $\mathbf{S I}$ ) was calculated to 

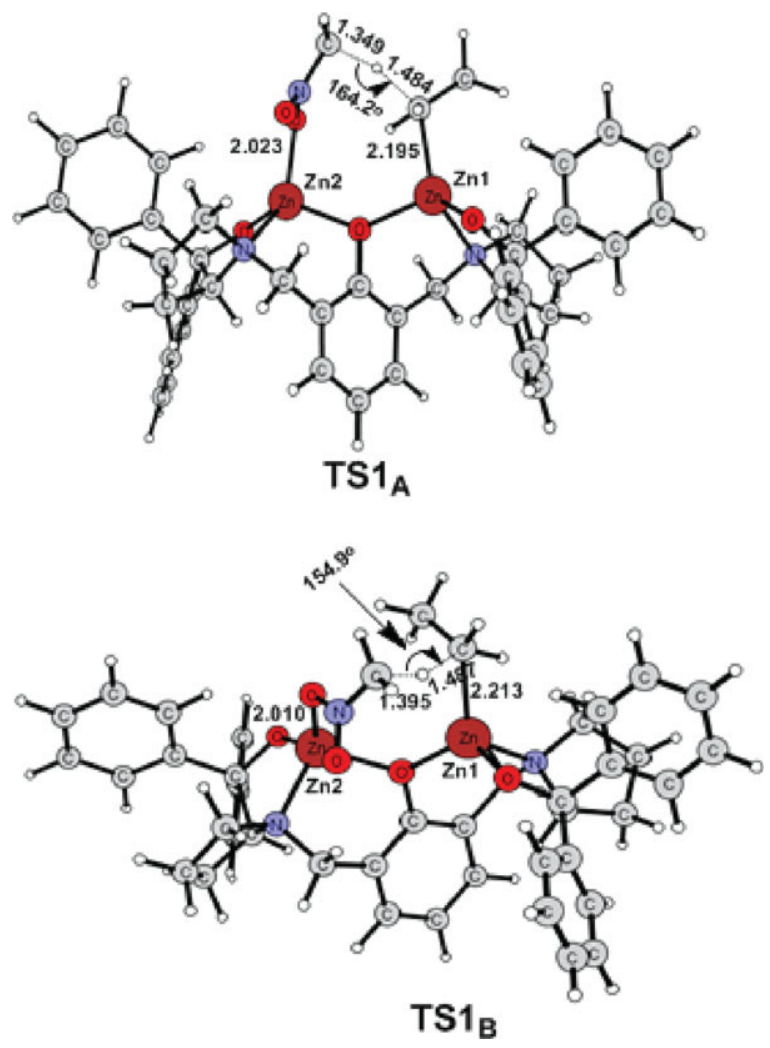

Figure 1. Optimized structures of the transition states for the proton transfer from nitromethane to the ethyl anion in two pathways (distances in $\AA$ ).

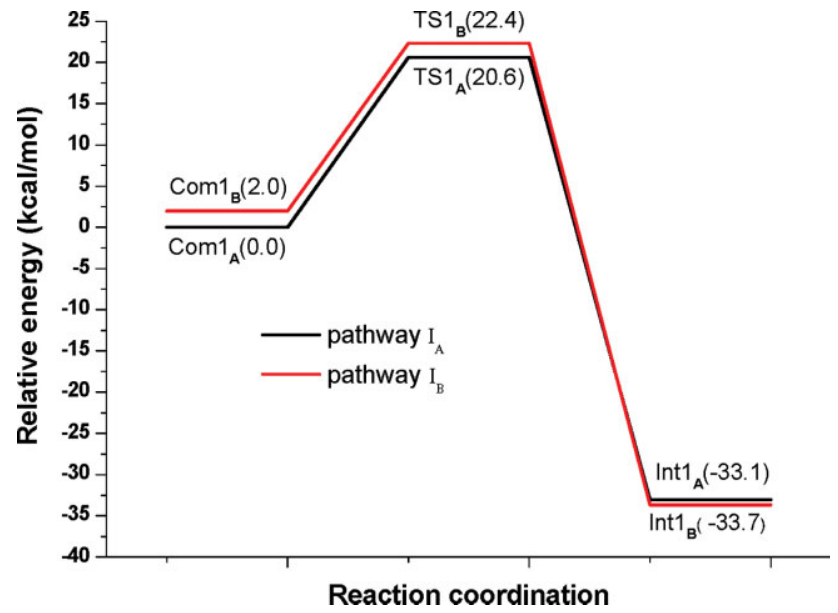

Figure 2. Calculated relative energetic ( $\mathrm{kcal} / \mathrm{mol})$ profile (including solvation) for the deprotonation step.

be endothermic by $7.3(7.7) \mathrm{kcal} / \mathrm{mol}$, indicating that the dinuclear zinc center provides more stabilization on the unprotonated product by as much as $8.3 \mathrm{kcal} / \mathrm{mol}$ in THF. However, the barrier for the catalytic $\mathrm{C}-\mathrm{C}$ bond formation does not change much compared with uncatalyzed one [8.6 (8.4) kcal/mol]. Our results are different from previous calculations on reaction between nitromethide and formaldehyde. ${ }^{49}$ The recent results show that the barrier and the reaction energy are 3.2 and -1.4 $\mathrm{kcal} / \mathrm{mol}$ at the CCSD(T)/aug-cc-pVDZ//MP2/6-31+G(d) level in gas phase. ${ }^{50}$ The main reason is due to the stronger hydrogen
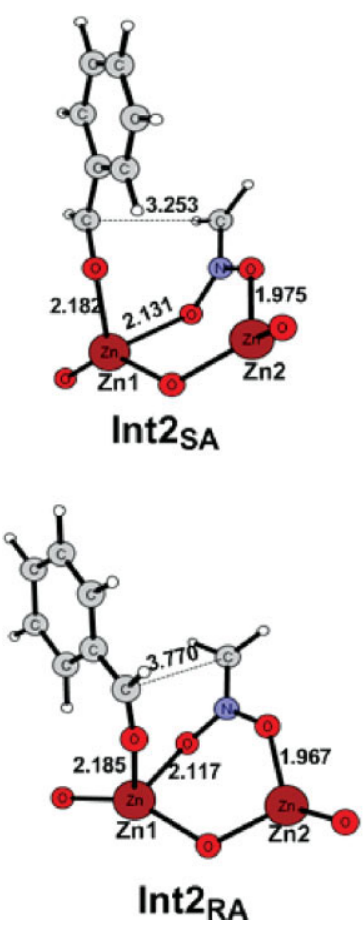
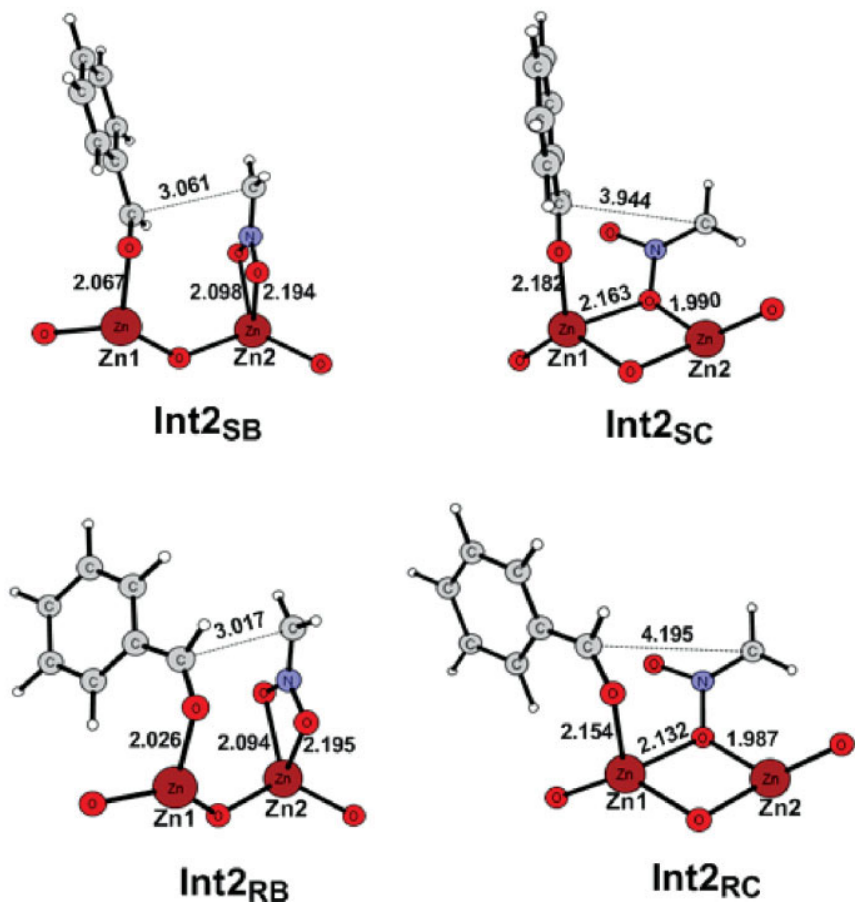

Figure 3. The six segments of the intermediates corresponding to three reaction pathways (distances in $\AA$ ). 


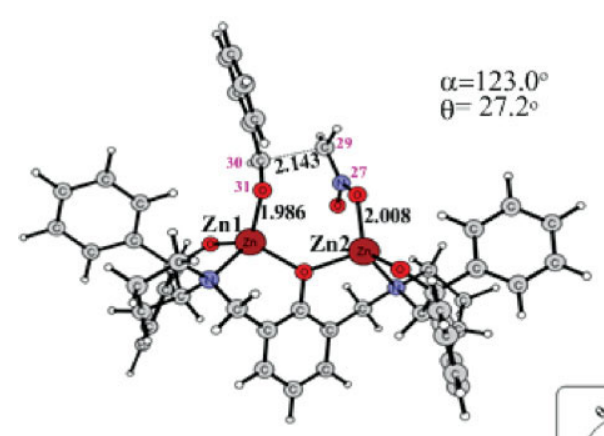

$\mathrm{TS} 2 \mathrm{SA} 0.0(0.0)$
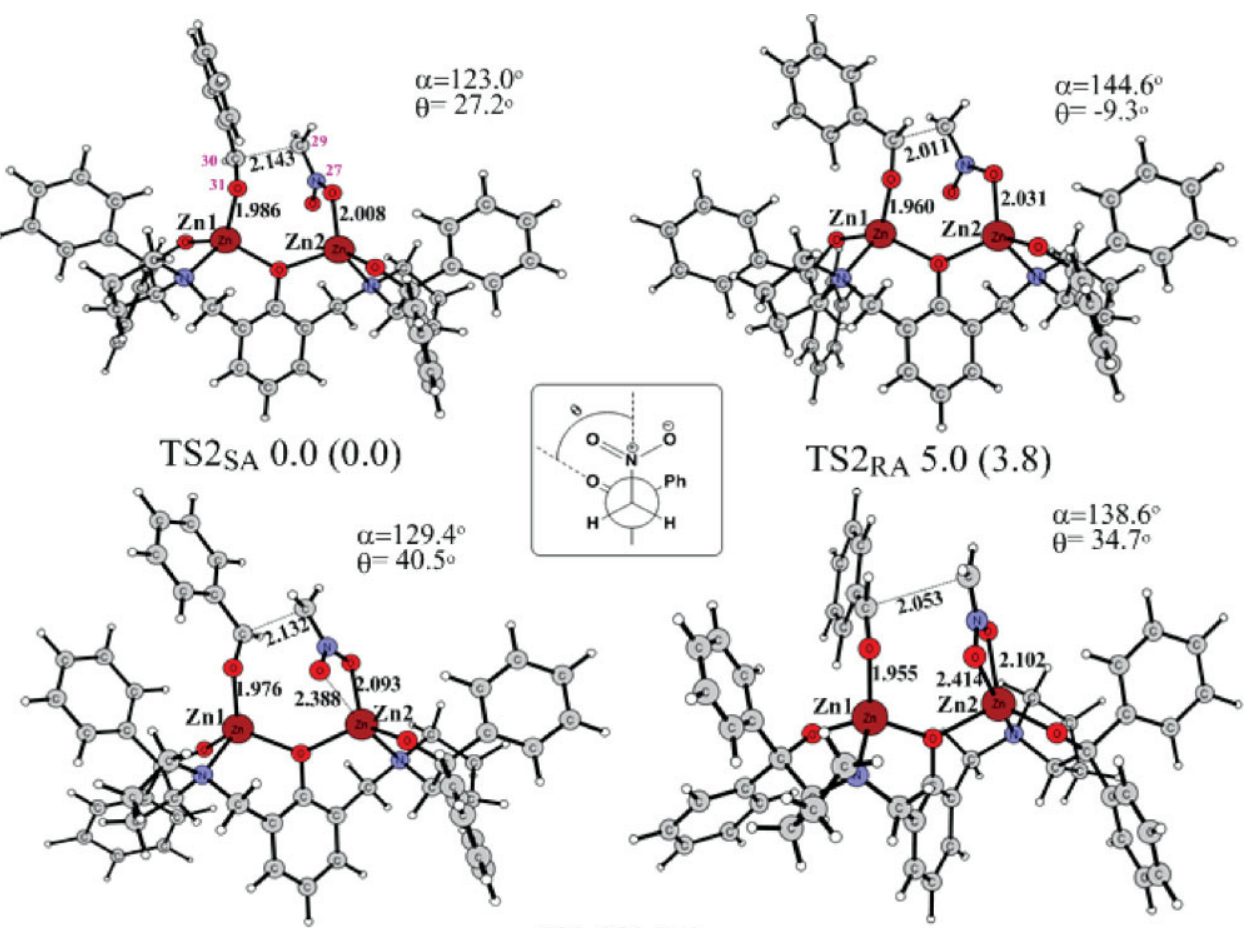

TS2 RA $5.0(3.8)$

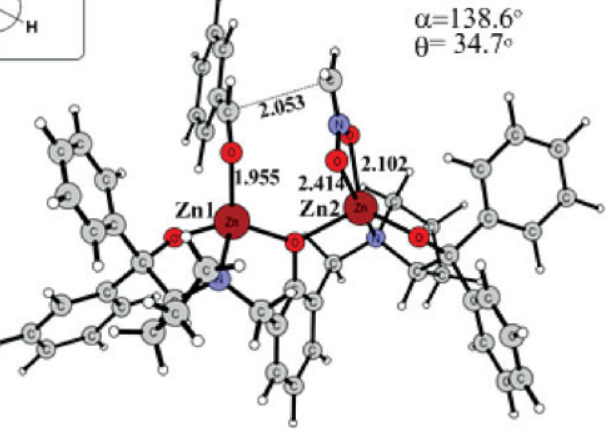

TS2 $2_{\mathrm{SB}} 0.4(1.4)$

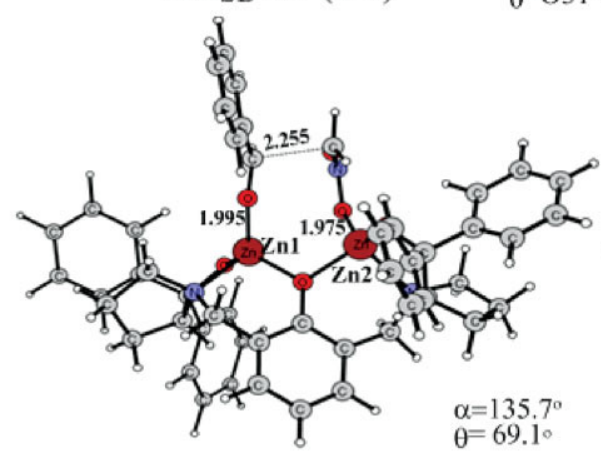

TS2sc $6.1(5.5)$
$\alpha=\mathrm{C} 30-031-\mathrm{Zn} 1$ $\theta^{-} \mathrm{O} 31-\mathrm{C} 30-\mathrm{C} 29-\mathrm{N} 27$
TS2 RB $4.8(4.5)$

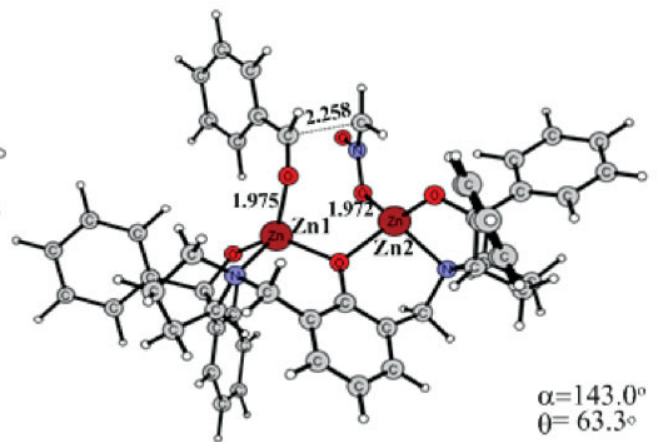

$\mathrm{TS} 2_{\mathrm{RC}} 7.3(6.5)$

Figure 4. The geometries of optimized transition states for $\mathrm{C}-\mathrm{C}$ bond formation through pathway $\mathrm{A}$ $\left(\mathrm{TS} 2_{\mathrm{SA}}, \mathrm{TS} 2_{\mathrm{RA}}\right)$, pathway $\mathrm{B}\left(\mathrm{TS} 2_{\mathrm{SB}}, \mathrm{TS} 2_{\mathrm{RB}}\right)$ and pathway $\mathrm{C}\left(\mathrm{TS} 2_{\mathrm{SC}}, \mathrm{TS} 2_{\mathrm{RC}}\right)$. Framed insets define the dihedral angles specified. Relative energies $(\mathrm{kcal} / \mathrm{mol})$ for the six transition states including solvation correction are given in the labels (gas phase values in parentheses) (distances in $\AA$ ).

bond between nitromethide and benzaldehyde comparing with that between nitromethide and formaldehyde, which stabilizes the reactant too much.

\section{Enantioselectivity}

It was found by Trost that this dinuclear $\mathrm{Zn}$ catalyst could catalyze many reactions with high efficiency and enantioselectivity. The reaction of benzaldehyde and nitromethane catalyzed by 5 mol\% catalyst proceeds with considerable asymmetric induction $(91 \%$ ee $) .{ }^{8}$ However, the reason for the high enantioselectivity in the reactions was not well elucidated so far. The phenyl rings of the diphenylcarbinol moiety were suggested to be involved in chiral recognition. ${ }^{22}$

In the present study, we have optimized the transition states leading to both enantiomers for all three pathways. We first note that the TS with the lowest energy ( $\mathrm{TS} 2_{\mathrm{SA}}$ ) corresponds to S-product, in agreement with the experimental findings that the major enantiomer of nitroaldol is S-configuration. ${ }^{8}$ The energy difference between $\mathrm{TS} 2_{\mathrm{SA}}$ and $\mathrm{TS} 2_{\mathrm{RA}}$ is 5.0 (3.8) $\mathrm{kcal} / \mathrm{mol}$, which has a gap with the experimentally observed ee of $91 \%$. However, with $\mathrm{BB} 1 \mathrm{~K}$ functional, the energy difference is 1.8 $\mathrm{kcal} / \mathrm{mol}$ in THF. So the method may have deviations, but all these results suggested that our results are consistent with the experimental trend. 


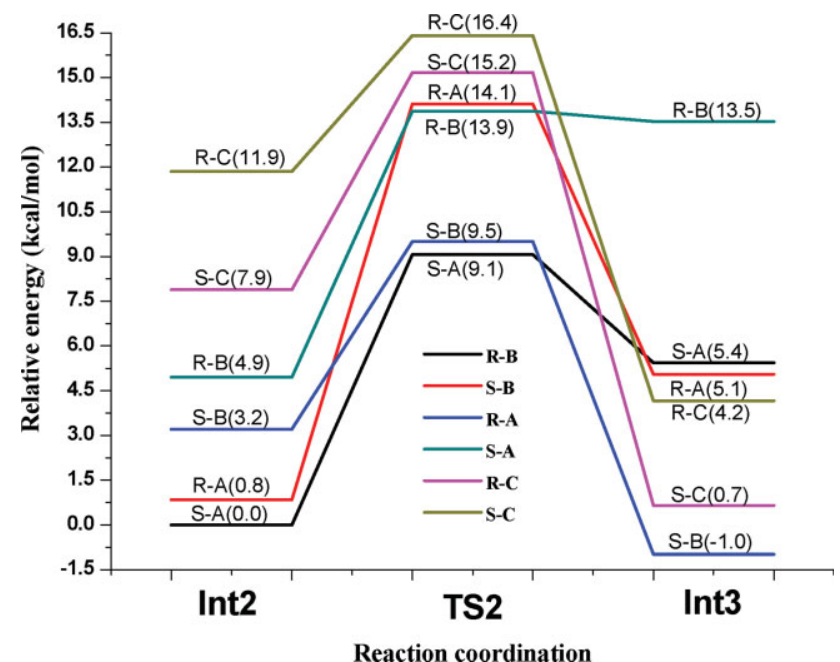

Figure 5. Calculated relative energetic $(\mathrm{kcal} / \mathrm{mol})$ profile for $\mathrm{C}-\mathrm{C}$ bond formation (including solvation). [Color figure can be viewed in the online issue, which is available at www.interscience.wiley.com.]
Table 1. Summary of the Calculated Relative Energies (kcal/mol) for the $\mathrm{C}-\mathrm{C}$ bond Formation Step Through Preferred Pathway A, for Catalyst with Four Phenyl Groups, or Four Methyl Groups and Four Hydrogen Atoms.

\begin{tabular}{lccc}
\hline & Phenyl- & $\mathrm{CH}_{3}-$ & $\mathrm{H}-$ \\
\hline Int2 & $0.0(0.0)$ & $0.0(0.0)$ & $0.0(0.0)$ \\
TS2 & $9.1(9.8)$ & $11.0(8.6)$ & $11.1(9.7)$ \\
Int3 & $5.4(6.0)$ & $7.4(4.7)$ & $7.2(5.6)$ \\
Int2 & $0.8(1.4)$ & $2.7(0.8)$ & $0.4(-0.3)$ \\
TS2 & $14.1(13.6)$ & $14.5(11.4)$ & $13.3(11.1)$ \\
Int3 & $5.1(2.2)$ & $6.6(1.0)$ & $3.3(-0.6)$ \\
\hline
\end{tabular}

We noticed that the Mulliken charge of C29 and C30 in Int $2_{\mathrm{SA}}$ is -0.143 and $+0.236 \mathrm{e}$, respectively; whereas it is -0.125 and +0.223 e in Int $2_{\mathrm{RA}}$. The stronger electrostatic interaction between $\mathrm{C} 29$ and $\mathrm{C} 30$ may result in lower barrier for the $\mathrm{C}-\mathrm{C}$ bond formation. In addition, we noted that the $\alpha$ angles (C30-O31-Zn1) in TS2 with S configurations are all smaller than those with $\mathrm{R}$ configurations (see Fig. 4). The reason should be
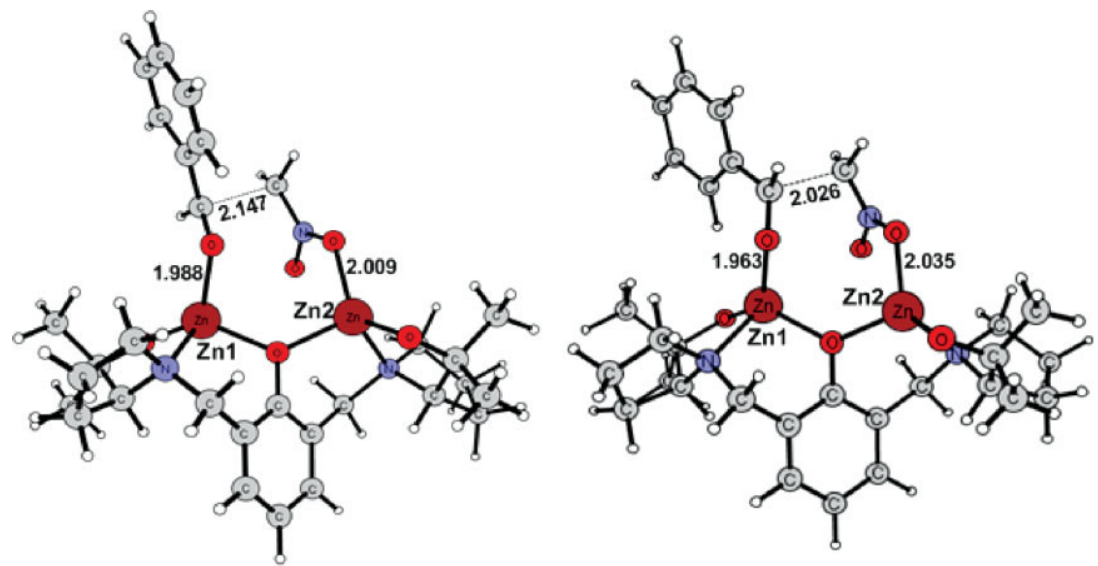

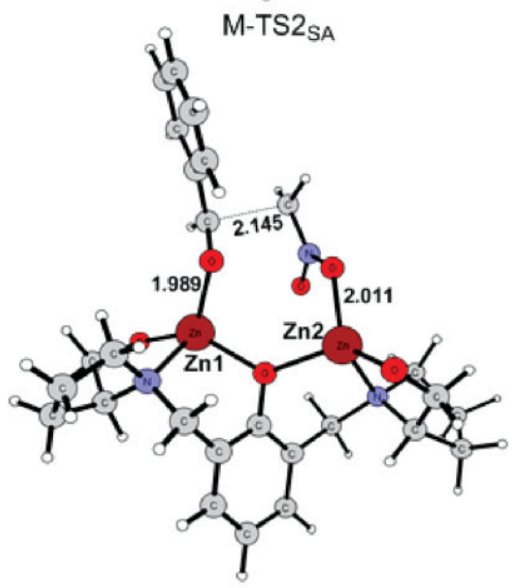

H-TS2

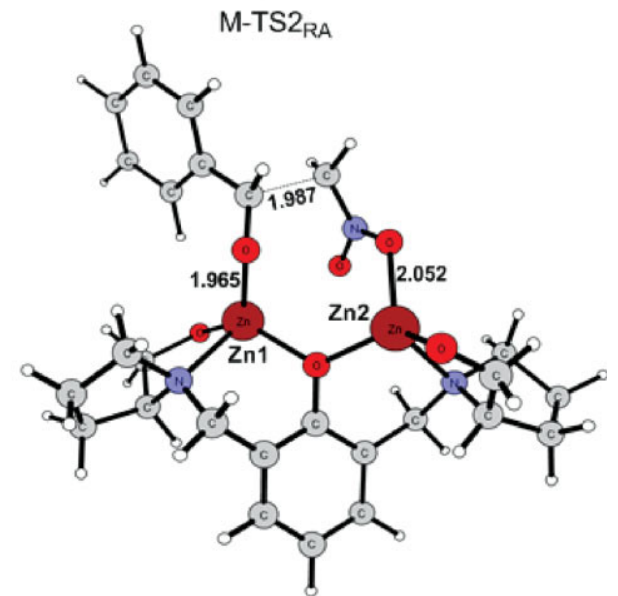

H-TS2 RA

Figure 6. The structures of the transition states for $\mathrm{S}$ and $\mathrm{R}$ products through more favored pathway A with phenyl groups substituted by methyl groups and hydrogen atoms (Distances in $\AA$ ). [Color figure can be viewed in the online issue, which is available at www.interscience.wiley.com.] 

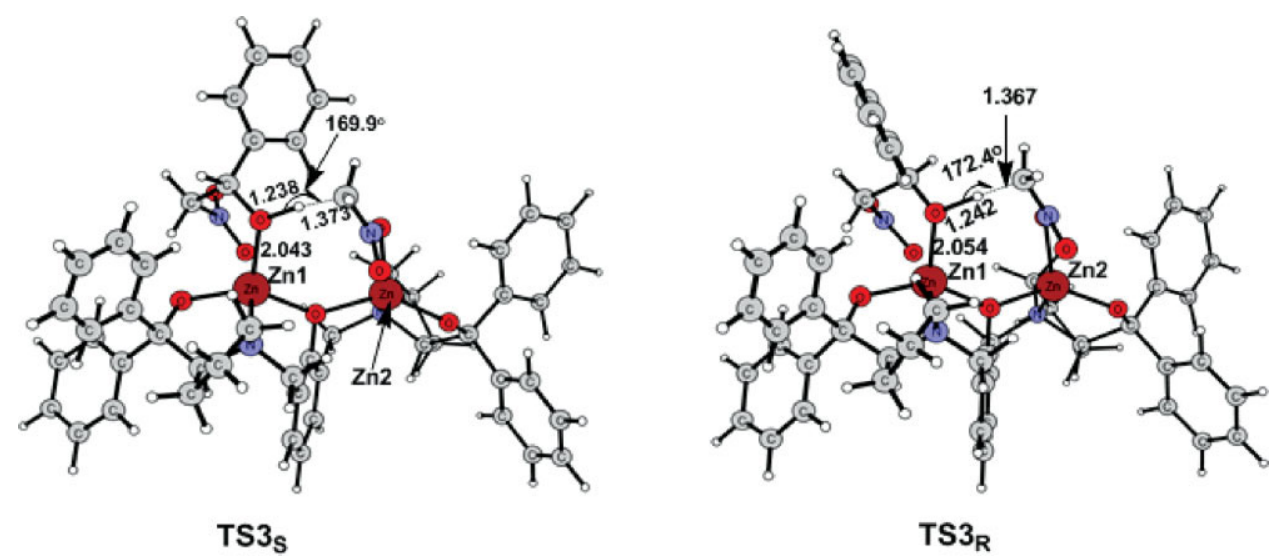

Figure 7. Optimized structures of the two transition states for the proton transfer from nitromethane to the nitroalkoxide oxygen anion (Distances in $\AA$ ). [Color figure can be viewed in the online issue, which is available at www.interscience.wiley.com.]

the steric repulsions between the phenyl ring of benzaldehyde and the carbinol oxygen coordinated to $\mathrm{Zn} 1$.

To clarify the role of the four phenyl rings in the catalyst, we have optimized the structures of the catalyst with phenyl groups replaced by methyl groups and hydrogen atoms. The structures of transition states (M-TS2 $2_{\mathrm{SA}}, \mathrm{M}-\mathrm{TS} 2_{\mathrm{RA}}$, and $\mathrm{H}-\mathrm{TS} 2_{\mathrm{SA}}, \mathrm{H}-\mathrm{TS} 2_{\mathrm{RA}}$ ) are shown in Fig. 6, whereas the structures of all intermediates are depicted in SI. As expected, the overall geometries are quite similar to the ones with phenyl groups discussed above. However, the energy difference for the two TS leading to $\mathrm{S}$ and $\mathrm{R}$ products becomes 3.5 (2.8) $\mathrm{kcal} / \mathrm{mol}$ for $\mathrm{CH}_{3}$-substituted catalyst, and $2.2(1.4) \mathrm{kcal} / \mathrm{mol}$ for H-substituted catalyst (see Table 1). Comparing with the energy difference of $5.0(3.8) \mathrm{kcal} / \mathrm{mol}$ in the phenyl-substituted catalyst, these results suggest that the larger the substitutes are, the better the enantioselectivity for this reaction is. That is to say, the phenyl rings play a key role in governing the enantioselectivity for this asymmetric reaction.

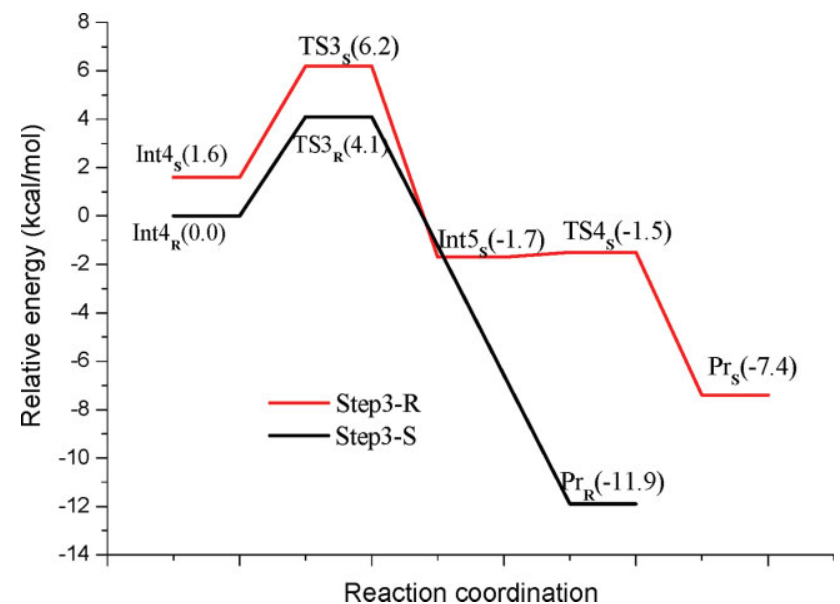

Figure 8. Calculated potential energy $(\mathrm{kcal} / \mathrm{mol})$ profile (including solvation) for step 3. [Color figure can be viewed in the online issue, which is available at www.interscience.wiley.com.]
Step 3: Proton Transfer

Trost and $\mathrm{Yeh}^{8}$ proposed that formation of $\mathrm{C}-\mathrm{C}$ bond would result in a nitroalkoxide, which can undergo protonation by a new nitromethane coordinated to $\mathrm{Zn} 2$. Such a proton transfer can generate a new reactive nitronate, and restart the catalytic cycle.

We found from our calculations that on the coordination of the other nitromethane, the S-complex $\left(\mathrm{Int}_{\mathrm{S}}\right)$ is $1.6 \mathrm{kcal} / \mathrm{mol}$ higher than R-complex $\left(\operatorname{Int} 4_{R}\right)$. The optimized transition states for the proton transfer $\left(\mathrm{TS}_{\mathrm{S}}\right.$ and $\left.\mathrm{TS} 3_{\mathrm{R}}\right)$ are shown in Figure 7. The barriers of the reactions are $4.6(5.2) \mathrm{kcal} / \mathrm{mol}$ and $4.1(5.1)$ $\mathrm{kcal} / \mathrm{mol}$ relative to Int $4_{\mathrm{S}}$ and Int $4_{\mathrm{R}}$, respectively (Fig. 8). In the $\mathrm{TS} 3_{\mathrm{S}}$, the transferred proton is sandwiched between the nitroalkoxide oxygen and the nitromethane carbon, with the $\mathrm{O}-\mathrm{H}$ and $\mathrm{C}-\mathrm{H}$ distance of $1.238 \AA$ and $1.373 \AA$, respectively. The main part of the $\mathrm{TS} 3_{\mathrm{R}}$ geometry is quite similar to that of $\mathrm{TS} 3_{\mathrm{S}}$, with the corresponding $\mathrm{O}-\mathrm{H}$ and $\mathrm{C}-\mathrm{H}$ distance of $1.242 \AA$ and $1.367 \AA$, respectively. At the end, the products complexed with the catalyst $\left(\operatorname{Pr}_{S}\right.$ and $\operatorname{Pr}_{R}$, see $\left.\mathbf{S I}\right)$ are formed, with a hydrogen bond between the nitronate oxygen and 2-nitro-1-phenylethanol. It was noted that an additional intermediate Int $5_{\mathrm{S}}$ (see SI) lies between $\mathrm{TS}_{\mathrm{S}}$ and $\mathrm{Pr}_{\mathrm{S}}$, with a hydrogen bond between the nitronate carbon and 2-nitro-1-phenylethanol. From Int5 $5_{S}$ to $\operatorname{Pr}_{S}$, we find a new transition state which is named as TS4 (see SI). It corresponds to the formation of a new hydrogen bond. The energy barrier is only $0.2 \mathrm{kcal} / \mathrm{mol}$ (Fig. 8), which suggests that the transformation is very fast.

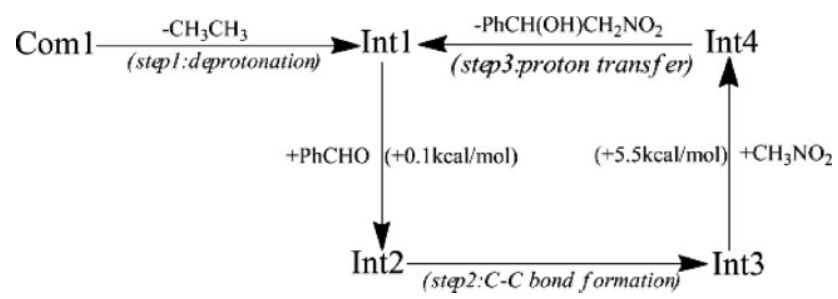

Scheme 4. Calculated catalytic cycle for the Henry reaction. 
Because the catalytic cycle contains just step 2 and step 3, our calculations suggest that step 2 determines the reaction kinetics, which is consistent with experimental results for the main product is S-configuration.

\section{Conclusions}

In the present paper, we have investigated the reaction mechanism and the enantioselectivity of the reaction of benzaldehyde and nitromethane catalyzed by the dinuclear zinc complex $\mathbf{1}$. The potential-energy profiles were calculated by means of DFT methods. Our calculations strongly support the experimentally proposed catalytic cycle as shown in Scheme 2 (See Scheme 4 for the calculating steps and energetics of some steps and involved species). The detailed mechanisms for all three steps are discussed, especially the enantioselectivity determining $\mathrm{C}-\mathrm{C}$ bond formation step.

For step 1, two plausible proton transfer channels involving the retention $\left(\mathrm{I}_{\mathrm{A}}\right)$ and the inversion $\left(\mathrm{I}_{\mathrm{B}}\right)$ of the configuration have been considered, with $\mathrm{I}_{\mathrm{A}}$ slightly preferred. For the $\mathrm{C}-\mathrm{C}$ bond formation step, three possible pathways (pathways A, B, C) have been found. Pathway A is energetically preferred over other two pathways. Both zinc ions are involved in stabilizing the negative charge in the transition states and intermediates. The enantioselectivity mainly comes from the steric repulsion between the benzaldehyde and the phenyls of the catalyst. The preferred S-product is in agreement with the experimental findings. In the following step, the proton transfer between the nitroalkoxide and a new nitromethane can generate the product nitroalcohol and a new reactive species ready for the next catalytic cycle. For the reaction cycle, the $\mathrm{C}-\mathrm{C}$ bond formation step is rate limiting.

We can speculate that this dinuclear zinc complex may catalyze other transformations ${ }^{20-24}$ through similar mechanistic issues. Theoretical studies of other catalytic $\mathrm{C}-\mathrm{C}$ bond formation reactions are in progress.

\section{Acknowledgments}

We thank Dr. Sven de Marothy (of Stockholm University) for providing xyz viewer to draw all the figures of the molecule models.

\section{References}

1. Henry, L. Acad Sci Ser C 1895, 120, 1265.

2. Luzzio, F. A. Tetrahedron 2001, 57, 915.

3. Boruwa, J.; Gogoi, N.; Saikia, P. P.; Barua, N. C. Tetrahedron: Asymmetry 2006, 17, 3315 .

4. Palomo, C.; Oiarbide, M.; Laso, A. Eur J Org Chem 2007, 16, 2561.

5. Sasai, H.; Suzuki, T.; Arai, S.; Arai, T.; Shibasaki, M. J Am Chem Soc 1992, 114, 4418.

6. Arai, T.; Yamada, Y. M. A.; Yamamoto, N.; Sasai, H.; Shibasaki, M. Chem Eur J 1996, 2, 1368.

7. Iseki, K.; Oishi, S.; Sasai, H.; Shibasaki, M. Tetrahedron Lett 1996, 37, 9081.
8. Trost, B. M.; Yeh, V. S. C. Angew Chem Int Ed 2002, 41, 861.

9. Palomo, C.; Oiarbide, M.; Laso, A. Angew Chem Int Ed 2005, 44, 3881.

10. Liu, S.; Wolf, C. Org Lett 2008, 10, 1831.

11. Bulut, A.; Aslan, A.; Dogan, Ö. J Org Chem 2008, 73, 7373.

12. Christensen, C.; Juhl, K.; Hazell, R. G.; Jørgensen, K. A. J Org Chem 2002, 67, 4875.

13. Evans, D. A.; Seidel, D.; Rueping, M.; Lam, H. W.; Shaw, J. T.; Downey, C. W. J Am Chem Soc 2003, 125, 12692.

14. Du, D.-M.; Lu, S.-F.; Fang, T.; Xu, J. J Org Chem 2005, 70, 3712.

15. Gan, C.-S.; Lai, G.-Y.; Zhang, Z.-H.; Wang, Z.-Y.; Zhou, M.-M. Tetrahedron: Asymmetry 2006, 17, 725.

16. Kogami, Y.; Nakajima, T.; Ashizawa, T.; Kezuka, S.; Ikeno, T.; Yamada, T. Chem Lett 2004, 33, 614.

17. Kogami, Y.; Nakajima, T.; Ikeno, T.; Yamada, T. Synthesis 2004, 12,1947

18. Machajewski, T. D.; Wong, C.-H. Angew Chem Int Ed 2000, 39, 1352.

19. Zhong, Y.-W.; Tian, P.; Lin, G.-Q. Tetrahedron: Asymmetry 2004, 15,771 .

20. Trost, B. M.; Ito, H. J Am Chem Soc 2000, 122, 12003.

21. Trost, B. M.; Ito, H.; Silcoff, E. R. J Am Chem Soc 2001, 123, 3367.

22. Trost, B. M.; Silcoff, E. R.; Ito, H. Org Lett 2001, 3, 2497.

23. Trost, B. M.; Fettes, A.; Shireman, B. T. J Am Chem Soc 2004, 126, 2660.

24. Trost, B. M.; Shin, S.; Sclafani, J. A. J Am Chem Soc 2005, 127, 8602.

25. Trost, B. M.; Terrell, L. R. J Am Chem Soc 2003, 125, 338.

26. Trost, B. M.; Jaratjaroonphong, J.; Reutrakul, V. J Am Chem Soc 2006, 128, 2778.

27. Trost, B. M.; Hitce, J. J Am Chem Soc 2009, 131, 4572.

28. Trost, B. M.; Weiss, A. H.; Wangelin, A. J.von. J Am Chem Soc 2006, 128, 8 .

29. Trost, B. M.; Mino, T. J Am Chem Soc 2003, 125, 2410.

30. Trost, B. M.; Müller, C. J Am Chem Soc 2008, 130, 2438.

31. Trost, B. M.; Yeh, V. S. C. Org Lett 2002, 4, 3513.

32. Trost, B. M.; Yeh, V. S. C.; Ito, H.; Bremeyer, N. Org Lett 2002, 4 , 2621.

33. Trost, B. M.; Frederiksen, M. U.; Papillon, J. P. N.; Harrington, P. E.; Shin, S.; Shireman, B. T. J Am Chem Soc 2005, 127, 3666.

34. Trost, B. M.; Weiss, A. H. Org Lett 2006, 8, 4461.

35. Vàzquez, J.; Peric'S, M. A.; Maseras, F.; Lledós, A. J Org Chem 2000, 65, 7303.

36. Rudolph, J.; Bolm, C.; Norrby, P. O. J Am Chem Soc 2005, 127, 1548 .

37. Meng, Q.-X.; Li, M.; Zhang, J.-S. J Mol Model 2006, 12, 294.

38. Wang, F.; Wang, J.-M.; Li, M. Struct Chem 2009, 20, 129.

39. Yamakawa, M.; Yamakawa, R. Organometallics 1999, 18, 128.

40. Becke, A. D. J Chem Phys 1993, 98, 5648.

41. Lee, C.; Yang, W.; Parr, R. G. Phys Rev B 1988, 37, 785.

42. Frisch, M. J.; Trucks, G. W.; Schlegel, H. B.; Scuseria, G. E.; Robb, M. A.; Cheeseman, J. R.; Montgomery, J. A.; Vreven, T, Jr.; Kudin, K. N.; Burant, J. C.; Millam, J. M.; Iyengar, S. S.; Tomasi, J.; Barone, V.; Mennucci, B.; Cossi, M.; Scalmani, G.; Rega, N.; Petersson, G. A.; Nakatsuji, H.; Hada, M.; Ehara, M.; Toyota, K.; Fukuda, R.; Hasegawa, J.; Ishida, M.; Nakajima, T.; Honda, Y.; Kitao, O.; Nakai, H.; Klene, M.; Li, X.; Knox, J. E.; Hratchian, H. P.; Cross, J. B.; Adamo, C.; Jaramillo, J.; Gomperts, R.; Stratmann, R. E.; Yazyev, O.; Austin, A. J.; Cammi, R.; Pomelli, C.; Ochterski, J. W.; Ayala, P. Y.; Morokuma, K.; Voth, G. A.; Salvador, P.; Dannenberg, J. J.; Zakrzewski, V. G.; Dapprich, S.; Daniels, A. D.; Strain, M. C.; 
Farkas, O.; Malick, D. K.; Rabuck, A. D.; Raghavachari, K.; Foresman, J. B.; Ortiz, J. V.; Cui, Q.; Baboul, A. G.; Clifford, S.; Cioslowski, J.; Stefanov, B. B.; Liu, G.; Liashenko, A.; Piskorz, P.; Komaromi, I.; Martin, R. L.; Fox, D. J.; Keith, T.; Al-Laham, M. A.; Peng, C. Y.; Nanayakkara, A.; Challacombe, M.; Gill, P. M. W.; Johnson, B.; Chen, W.; Wong, M. W.; Gonzalez, C.; Pople, J. A. Gaussian 03, Revision D.01; Gaussian, Inc.: Pittsburgh, PA, 2004.

43. Bergner, A.; Dolg, M.; Kuechle, W.; Stoll, H.; Preuss, H. Mol Phys 1993, 80, 1431.

44. Barone, V.; Cossi, M. J Phys Chem A 1998, 102, 1995.
45. Cammi, R.; Mennucci, B.; Tomasi, J. J Phys Chem A 1999, 103, 9100.

46. Klamt, A.; Schmmrmann, G. J Chem Soc Perkin Trans 1993, 2, 799.

47. Tomasi, J.; Mennucci, B.; Cammi, R. Chem Rev 2005, 105, 2999.

48. Zhao, Y.; Lynch, B. J.; Truhlar, D. G. J Phys Chem A 2004, 108, 2715.

49. Lecea, B.; Arrieta, A.; Morao, I.; Cossío, F. P. Chem Eur J 1997, 3 , 20.

50. Zorn, D.; Lin, V. S. Y.; Pruski, M.; Gordon, M. S. J Phys Chem A 2008, 112, 10635 . 